\title{
Immunosuppression and its complications
}

\section{Eberhard Gunsilius}

Received: 7 August 2019 / Accepted: 7 August 2019

(C) Springer-Verlag GmbH Austria, part of Springer Nature 2019

Acquired immunosuppression can be disease related, e.g. due to infection by human immunodeficiency virus (HIV) or iatrogenic after organ transplantation or during treatment of chronic diseases such as rheumatic disorders. Immunosuppressed patients require vigilant monitoring regarding a plethora of potential complications allowing their early detection and appropriate management. In this issue of MEMO, four articles address selected aspects of immunosuppression. Hartmann and Atzl [1] provide an overview about HIV-associated lymphomas. Krapf and Pierer [2] describe the surgical approach to skin cancer as a common complication in patients after organ transplantation. Neuwirt et al. [3] give a comprehensive overview about the strategies for the prevention of renal allograft rejection and their potential complications including the risk and management of infections and the development of skin cancer and lymphoproliferative diseases. Patients with autoimmune diseases or chronic inflammatory conditions often receive long-term immunosuppressive treatment. The article written by Rudzki [4] illustrates the risk of malignancy in such patients.

I hope you will find these contributions interesting and informative and I would like to take the opportunity to express my gratitude to the authors for their work.

Eberhard Gunsilius, M.D.

Conflict of interest E. Gunsilius declares that he has no competing interests.

\section{Univ.-Doz. Dr. med. E. Gunsilius, M.D. (凹)}

Department for Hematology and Medical Oncology, Medical

University Innsbruck, Anichstraße 35, 6020 Innsbruck,

Austria

eberhard.gunsilius@tirol-kliniken.at

\section{References}

1. Hartmann BL, Atzl MD. HIV-triggered Lymphoma. Memo. 2019;12(3). https://doi.org/10.1007/s12254-019-00518-7.

2. Krapf J, Pierer G. Skin tumours in organ transplant recipients-implications for the plastic surgeon. Memo. 2019;12(3). https://doi.org/10.1007/s12254-019-0504-7.

3. Neuwirt H, Rudnicki M, Schratzberger P, Pirklbauer M, Kronbichler A, Mayer G. Immunosuppression after renal transplantation. Memo. 2019;12(3). https://doi.org/10. 1007/s12254-019-0507-4.

4. Rudzki JD. Risk of malignancy of autoimmune disorders after long-term therapy with Corticoids or DMARDs-a controversial issue. Memo. 2019;12(3). https://doi.org/10. 1007/s12254-019-0506-5.

Publisher's Note Springer Nature remains neutral with regard to jurisdictional claims in published maps and institutional affiliations.

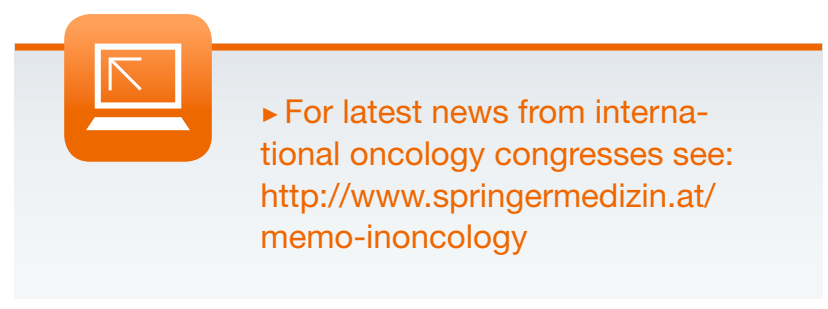

